\title{
Identification and antimicrobial susceptibilities of Enterobacter species isolated from clinical specimen in southeastern Turkey from 2015 to 2017
}

\begin{abstract}
Background/aim: Enterobacter species often colonise human gastrointestinal tract, causing various opportunistic infections. Enterobacter cloacae and Enterobacter asburiae are the most frequently isolated Enterobacter species. The aim of this research was to investigate antimicrobial resistance among Enterobacter spp. strains isolated from patients in a tertiary hospital of Southeastern Turkey. There are few publications on antibiotic resistance of Enterobacter species.

Materials and methods: This retrospective study included Enterobacter spp. strains isolated from clinical specimen sent from Dicle University Hospital clinics from 2015 to 2017. The isolates to be considered as infection agents were identified by MALDI-TOF mass spectrometry. The antimicrobial susceptibility test (AST) was carried out by semiautomated microbiology system and evaluated according to EUCAST v.8.0 criteria.

Results: A total of 296 (93 in 2015, 96 in 2016, and 107 in 2017) Enterobacter spp. strains was were isolated over three-years period. The most frequently identified species was $E$. cloacae (240 strains, $81.1 \%$ ). The highest resistance was found against aztreonam $(41.8 \%)$ and ceftazidim (41.9\%) while lowest resistance was against amikacin, meropenem and ciprofloxacin. Conclusion: Amikacin and meropenem were the most effective antibiotics against $E$. cloacae. The resistance rates of other Enterobacter strains other than E. cloacae varied according to years and species.
\end{abstract}

Keywords: Enterobacter cloacae, antibiotic resistance, amikacin, meropenem
Volume 8 Issue I - 2020

\section{Nida ÖZCAN, Salim YAKUT, Neslihan GENIȘEL, Selahattin ATMACA \\ Department of Medical Microbiology, Dicle University, Turkey}

Correspondence: Nida ÖZCAN, Dicle University Faculty of Medicine, Department of Medical Microbiology, Diyarbakır, Turkey,Tel+905052710103, Email nida.ozcan@dicle.edu.tr

Received: December 27, 2019 | Published: January 31, 2020

\section{Introduction}

Enterobacter species are members of human gut microbiota. These facultative anaerobe Gram negative rods may cause opportunistic infections especially in immunocompromised patients. ${ }^{1}$ Hoffman et al. described E.cloacae, E.asburiae, E.hormaechei and E.kobei species as "E.cloacae complex" in 2005..$^{2-5}$ Enterococcus faecium, Staphylococcus aureus, Klebsiella pneumoniae, Acinetobacter baumanni, Pseudomonas aeruginosa ve Enterobacter spp. are important infectious agents which are briefly named as "ESKAPE" pathogens. Enterobacter species may have multiple drug resistance with porine loss, efflux system activation, AmpC cephalosporinase and metallo-betalactamase enzyme systems. ${ }^{6}$ In particular, carbapenem resistant isolates with blaNDM1 and blaKPC enzymes have been reported to cause serious nosocomial outbreaks in different countries. ${ }^{5,7-9}$ The most frequently isolated Enterobacter species have been reported as E.cloacae, E.aerogenes and E.asburiae worldwide. ${ }^{5}$ Microscobic examination of the specimen is important to determine whether bacteria isolated in culture are causative agents of infection. Number of leucocytes indicates whether the culture growing bacteria were infectious agents or colonizers. ${ }^{10,11}$ The $\mathrm{Q}$ score assessment indicates the number of polymorphonuclear cells (PMN) with positive values and the number of squamous epithelial cells (SEC) with negative values directly seen in Gram-stained smears of wounds. ${ }^{12}$ Matrix-assisted laser desorption/ionization- time of flightmass spectrometry (MALDI-TOF-MS) has been used as a tool for bacterial identification in the last decades. The system provides fast and easy identification of bacteria that grow in culture. ${ }^{4,13}$ Articles on Enterobacter species alone are quite limited in our country. Current study aims to identify and determine antibiotic susceptibility of Enterobacter species isolated from various clinical samples in our laboratory between 2015-2017.

\section{Materials and methods}

The approval form of this retrospective study was obtained from Dicle University Ethics Committee (No: 124) in March 2019. Enterobacter strains isolated from different specimen sent from clinics of Dicle University Hospital between January 2015 and December 2017 were included in the study. Cerebrospinal fluid (CSF), pleural fluid, peripheral and catheter blood samples were taken into Bactec Plus aerobic / F or BD Bactec Peds Plus / F bottles and incubated in BACTEC FX (Becton Dickinson, USA) system. Bottles with bacterial growth signal were subcultured on solid media. For the respiratory tract and wound samples, Bartlett and Q scoring methods of microscobic examination were used to determine whether the isolate was an infectious agent. ${ }^{10}$ The same bacteria grown in both catheter and peripheral blood samples was taken as causative agent of catheter-related bloodstream infections. Bacterial growth of the catheter samples with no growth in the peripheral blood culture was evaluated as contamination or colonization. ${ }^{14}$ The causative agents according to Gram staining and culture growing profiles were identified with MALDI-TOF mass spectrometry by Maldi Biotyper (Bruker, U.S.A). Antibiotic susceptibility tests (AST) were performed with Phoenix 100 (Becton Dickinson, U.S.A) automated system by using Phoenix UNMIC-401 and NMIC-400 ID panels respectively for urine and other samples. EUCAST v.8.0 criteria were used for the evaluation of antimicrobial susceptibility tests. ${ }^{15}$ 


\section{Results}

A total of 296 (93 in 2015, 96 in 2016 and 107 in 2017) Enterobacter spp. strains were isolated over three years' time. About $72 \%(\mathrm{n}=213)$ of the bacteria were isolated from clinical or intensive care patients while $28 \%(n=83)$ were isolated from outpatients. $153(51.7 \%)$ of the patients were male and $143(48.3 \%)$ were female. The most common isolates were urine (138 specimen, 46.6\%), blood (44 specimen, $14.9 \%$ ) and wound (35 specimen, $11.8 \%)$. Tracheal aspirate (23 specimen, $7.8 \%)$, tissue and abscess (17 specimen, $5.7 \%)$, catheter $(7$ samples, $2.4 \%$ ), sputum (6 samples, $2 \%$ ) and other samples (pleural, peritoneal, synovial and cerebrospinal fluids, bile, ear drainage, bronchoalveolar lavage; 26 samples, 8.8\%) were also evaluated. Microscopic examination results were taken into consideration when evaluating culture results in the majority of samples. Bacterial growth in samples with abundant leukocytes and no epithelium was evaluated as the causative agent of infection (Figure 1). The most frequently identified species were E.cloacae (240 strains, $81.1 \%$ ) and E.asburiae (29 strains, 9.8\%) while 9 species (3\%) could not be identified up to species level (Figure 2). Amikacin was found to be the most effective antibiotic against all Enterobacter isolates. Resistance rates to amikacin was found to be $5.1 \%$ among E. cloacae and $1.9 \%$ among other Enterobacter species. Gentamicin resistance rates were $24.6 \%$ among E.cloacae and 5.7\% among other species. Meropenem resistance rates were found to be $10.3 \%$ and $16.4 \%$ among E.cloacae and other species, respectively. Approximately one third of all isolates were resistant to beta-lactam antibiotics (ceftazidime, cefixime and aztreonam). Ciprofloxacin resistance was found to be $21.2 \%$ and $11.1 \%$ among E. cloacae and other Enterobacter strains, respectively. Approximately one third of all isolates were resistant to beta-lactam antibiotics (ceftazidime, cefepime and aztreonam). Trimethoprimsulfamethoxazole resistance rates among E. cloacae and other species were as $31.1 \%$, and $10.9 \%$, respectively (Table 1 ).

Tablo I Antimicrobial susceptibility test (AST) results of Enterobacter spp. strains isolated between 2015- 2017 [number of resistant strains/ number of total strains (resistance rate\%)]

\begin{tabular}{|c|c|c|c|}
\hline $\begin{array}{l}\text { Species } \\
\text { Antibiotics }\end{array}$ & E.cloacae & Other species* & Total \\
\hline Gentamicin & $58 / 236(24.6)$ & $3 / 53(5.7)$ & $61 / 289(21.1)$ \\
\hline Amikacin & $12 / 237(5.1)$ & $1 / 53(1.9)$ & $13 / 290(4.5)$ \\
\hline Ceftazidime & III/233(47.8) & $8 / 5 I(15.7)$ & $119 / 284(41.9)$ \\
\hline Cefepime & $97 / 228(42.5)$ & $7 / 54(I 3)$ & I I4/330(40.4) \\
\hline Aztreonam & $107 / 229(46.8)$ & $|0 / 5|(19.6)$ & I I7/280(4I.8) \\
\hline Meropenem & $24 / 234(10.3)$ & $9 / 55(16.4)$ & $33 / 289(I I .4)$ \\
\hline SXT** & $74 / 238(31.1)$ & $6 / 55(10.9)$ & $80 / 293(27.3)$ \\
\hline Ciprofloxacin & $50 / 236(21.2)$ & 6/54(II.I) & $56 / 34 I(19.3)$ \\
\hline
\end{tabular}

*:E. asburiae, E. kobei, E. amnigenus, E. gergoviae, E, ludwigi, E. hormaechei,

$P$. agglomerans ve unidentified species

**:Trimetoprim/sulfametoxazole

\section{Discussion}

Enterobacter species frequently caused nosocomial infections in recent decades. Researchers reported carbapenem-resistant Enterobacter species as serious nosocomial agents with a high mortality rate. Hong et al. ${ }^{1}$ reported 51 colistin resistant strains among 213 E. cloacae isolates in Korea. Carbapenem resistant E. cloacae strains were reported by Jin et al. ${ }^{1,4,5,7}$ \& Öğünç et al. ${ }^{16}$ found the resistance rates of imipenem, cefepime and amikacin as $2 \%, 9 \%$ and $31 \%$, respectively, among 45 Enterobacter strains (E. cloacae and 11 E. aerogenes). İmipenem and cefepime were the most effective antibiotics while amikacin resistance was relatively high in that study. In the same study cefotaxime and ceftazidime resistance were found as $67 \%$ and $64 \%$, respectively. ${ }^{16}$ It was found that $41.9 \%$ of total isolates were resistant to ceftazidime and $40.4 \%$ were resistant to cefepime. In a surveillance study, Aksaray et al. ${ }^{17}$ reported that among 50 Enterobacter strains isolated as nosocomial agents $68 \%$ of strains were resistant to ceftazidime, $28 \%$ to cefepime and $66 \%$ to cefotaxime. ${ }^{17}$ In the same study, imipenem was found to be the most effective antibiotic with a resistance rate of $4 \%$, followed by ciprofloxacin, cefepime and amikacin with $8 \%, 28 \%, 32 \%$ resistance rates, respectively. ${ }^{17}$ Kaleli et al. ${ }^{18}$ evaluated antimicrobial resistance of 109 Enterobacter strains; $15 \%$ of the strains were resistant to amikacin, while resistance to ceftazidime, ceftriaxone, cefaclor and cephalotine were found as $47 \%, 50 \%, 72 \%$ and $83 \%$, respectively. ${ }^{18}$ Yazıc1 et al. ${ }^{19}$ obtained the lowest resistance against amikacin $(2.4 \%)$ followed by imipenem (2.4\%) and ciprofloxacin (2.4\%) in 120 Enterobacter isolates obtained from 42 outpatients and 78 inpatients. ${ }^{19}$ The antibiotics resistance rates of Enterobacter strains isolated from Dicle University hospital clinics between 2005-2007 were determined according to the Clinical \& Laboratory Standards Institute (CLSI) criteria. Meropenem and amikacin were found to be the most effective antibiotics for E.aerogenes and E.cloacae strains. ${ }^{20}$ The resistance rates of both meropenem and amikacin among Enterobacter strains isolated between 2005-2007 were reported as \%3. In current study the resistance rate for the meropenem and amikacin were $11.4 \%$ and $4.5 \%$, respectively. Resistance to ciprofloxacin was reported as $27 \%$ among Enterobacter strains isolated by by Öğünç et al. ${ }^{16} \mathrm{Ciprofloxacin}$ resistance among Enterobacter isolates were reported as $11.5 \%$ in inpatients and $4.8 \%$ in outpatients by Yazıc1 et al. ${ }^{19}$ Ciprofloxacin resistance was reported as $15 \%$ by Kaleli et al. ${ }^{18}$ in 2001 , and as $19 \%$ by Gülhan et al. ${ }^{18,20}$ In our study, it was found to be $19.3 \%$, consistent with previous studies. Multi-drug resistant Enterobacter isolates have been reported to be a worldwide problem. Determination of drug resistance mechanisms are indicated to be important for treatment especially in carbapenemase producing isolates. ${ }^{78}$ Tarumoto et al. ${ }^{21}$ identified a blaIMI-1 secreting colistin-heteroresistant E.cloacae in an article published in 2018. The strains were reported to be resistant to cephalosporins (except fourth generation), carbapenems, levofloxacin and aminoglycosides. ${ }^{21}$

Kyaung Hong et al. investigated antibiotics resistance in colistin-resistant Enterobacter spp strains in their articles in 2018. Among 51 colistin-resistant E. cloacae isolates; meropenem, gentamicin, cefepime, ciprofloxacin, ceftazidime and trimethoprim / sulfomethoxazole resistance rates were found as $2 \%(1$ isolate), $2 \%(1$ isolate), $9.8 \%$ (5 isolates), $19.6 \%$ (10 isolates), $47.1 \%(24$ isolates) and 52.9(27 isolates), respectively. ${ }^{1}$ Among 6 colistin-resistant E. aerogenes isolates; meropenem, cefepime, gentamicin, ciprofloxacin, ceftazidime and trimethoprim/sulfomethoxazole resistant rates were $16.7 \%$ ( 1 isolate), $16.7 \%$ ( 1 isolate), $50 \%$ (3 isolates), 50\%(3 isolates), $83.3 \%\left(5\right.$ isolates) and $83.3 \%(5$ isolates $)$, respectively. ${ }^{1}$ In two articles published in 2016, researchers reported that colistin has failed in some treatments due to colistin resistance; E.cloacae and E.aerogenes species as opportunistic pathogens that can cause serious problems for human health..$^{22,23}$ In a study conducted in Brazil in 2018, the researchers evaluated the resistance profiles of 14 Enterobacter 
isolates ( 8 E.cloacae and 6 E.aerogenes) to different antibiotics. All strains were resistant to sulfonamide, $12(85.7 \%)$ strains to cefaclor and nitrofurantoine, $11(78.6 \%)$ strains to doxycycline, $6(42.9 \%)$ strains to ertapeneme, $5(35.7 \%)$ strains to ceftazidime, cefepime and ceftriaxona, $4(28.6 \%)$ strains were found to be resistant to amikacin, gentamicin, tobramycin, ofloxacin, cefotaxime and aztreonama, $3(21.4 \%)$ strains were resistant to ciprofloxacin, levofloxacin and tetracycline, $2(14.3 \%)$ strains to meropenem and $1(7.1 \%)$ to chloramphenicole. ${ }^{9}$

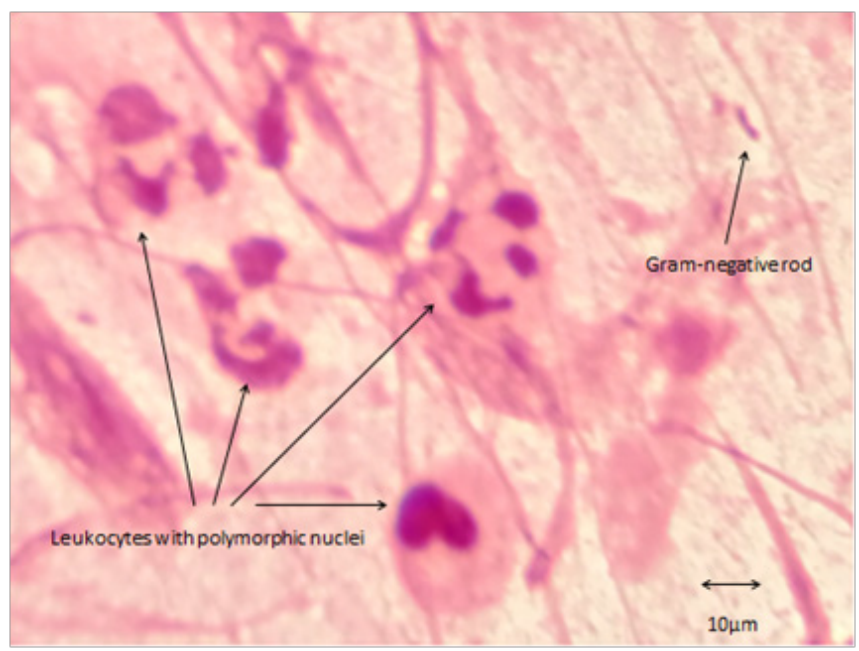

Figure I Gram staining image of a tracheal aspirate sample (with x1000 magnification) The bacteria was determined as infectious agent due to leucocytes with polymorphic nuclei.

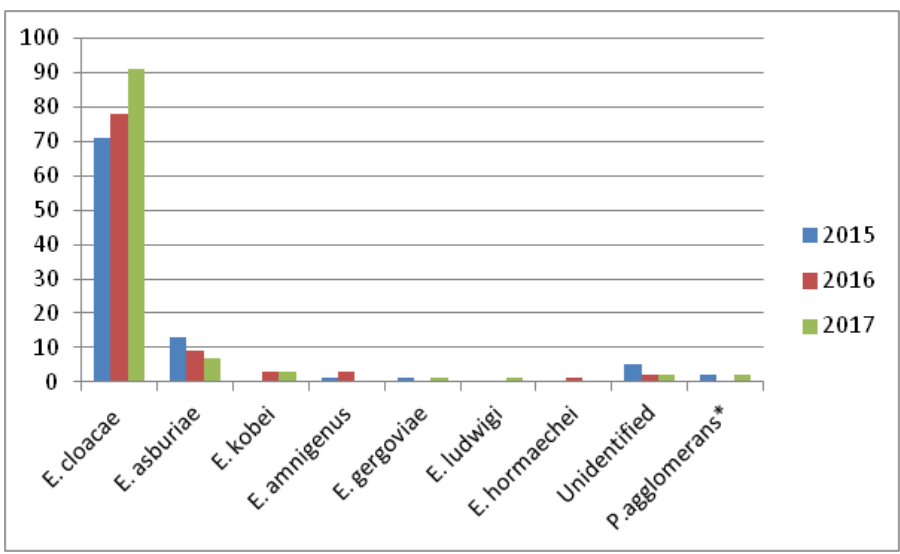

Figure 2 Distribution of Enterobacter spp. strains isolated from clinical specimen from 2015 to 2017.

*Pantoea agglomerans

\section{Conclusion}

Amikacin, an aminoglycoside, was an effective antibiotic against all Enterobacter isolates and the resistance rate of meropenem was higher in other Enterobacter species compared to E. cloacae strains. In this study, it was emphasized that microscopic examination contributed to the evaluation of culture results. It was also emphasized that mass spectrometry stands as a novel and current bacterial identification method.

\section{Funding details}

None.

\section{Acknowledgements}

None.

\section{Conflicts of interest}

The author declares no conflict of interest.

\section{References}

1. Hong YK, Lee JY, Ko KS. Colistin resistance in Enterobacter spp. isolates in Korea. J Microbiol. 2018;56(6):435-440.

2. Brady C, Cleenwerck I, Venter S, et al. Taxonomic evaluation of the genus Enterobacter based on multilocus sequence analysis (MLSA): proposal to reclassify E. nimipressuralis and E. amnigenus into Lelliottia gen. nov. as Lelliottia nimipressuralis comb. nov. and Lelliottia amnigena comb. nov. Syst Appl Microbiol. 2013;36(5):309-319.

3. Yoon JW, Wanderman NR, Kerezoudis P, et al. Enterobacter Infection after Spine Surgery: An Institutional Experience. World Neurosurg. 2019;123:e330-e337

4. De Florio L, Riva E, Giona A, et al. MALDI-TOF MS Identification and Clustering Applied to Enterobacter Species in Nosocomial Setting. Front Microbiol. 2018;9:1885.

5. Hoffmann H, Stindl S, Ludwig W, et al. Reassignment of Enterobacter dissolvens to Enterobacter cloacae as E. cloacae subspecies dissolvens comb. nov. and emended description of Enterobacter asburiae and Enterobacter kobei. Syst Appl Microbiol. 2005;28(3):196-205.

6. Rice LB. Progress and Challenges in Implementing the Research on ESKAPE Pathogens. Infect Control Hosp Epidemiol. 2010;31(S1):S7-10.

7. Jin C, Zhang J, Wang Q, et al. Molecular Characterization of Carbapenem-Resistant Enterobacter cloacae in 11 Chinese Cities. Front Microbiol. 2018;9:1597.

8. Hao M, Ye M, Shen Z, et al. Porin Deficiency in Carbapenem-Resistant Enterobacter aerogenes Strains. Microb Drug Resist. 2018;24(9):12771283.

9. Azevedo PAA, Furlan JPR, Oliveira-Silva M, et al. Detection of virulence and $\beta$-lactamase encoding genes in Enterobacter aerogenes and Enterobacter cloacae clinical isolates from Brazil. Brazilian $J$ Microbiol. 2018;49:224-228.

10. Zeytinoğlu Türkeş A, Levent B, Esen B, et al. For Medical Specialists: Practice Guide From Clinical Sample To Final Report-Skin, Soft Tissue Samples, Eye Samples. 2015.

11. Klinik Örnekten Sonuç Raporuna Uygulama Rehberi-Genital Sistem Örnekleri. 2015.

12. Matkoski C, Sharp SE, Kiska DL. Evaluation of the Q score and Q234 systems for cost-effective and clinically relevant interpretation of wound cultures. J Clin Microbiol. 2006;44(5):1869-1872.

13. Nagy E, Becker S, Kostrzewa M, et al. The value of MALDI-TOF MS for the identification of clinically relevant anaerobic bacteria in routine laboratories. J Med Microbiol. 2012;61(Pt 10):1393-400.

14. Baysallar M, Erensoy MS, Esen B, et al. Practice Guide for Medica Microbiology Experts from Clinical Sample to Final Report-Blood Circulation Samples. 2017. 
15. EUCAST. European Committee on Antimicrobial Susceptibility Testing Breakpoint tables for interpretation of MICs and zone diametersVersion 8.0. 2018.

16. Öğünç D, Gültekin M, Günseren F, Çolak D, Öngüt G, Mamıkoğlu L. Nozokomial Enterobacter Suşlarının Antibiyotik Duyarlılık Özellikleri. ANKEM Derg. 1999;13(1):33-8.

17. Aksaray S, Dokuzoguz B, Guvener E, et al. Surveillance of antimicrobia resistance among Gram-negative isolates from intensive care units in eight hospitals in Turkey. J Antimicrob Chemother. 2000;46(4):649649 .

18. Kaleli İ, Demir M, Maralcan M, Öztürk S. Enterobacter Suşlarının Antibiyotik Duyarlılıklarının Değerlendirilmesi. ANKEM Derg. $2001 ; 15(1): 140-4$

19. Yazıcı Y, Aydın F, Tosun İ, Kaklıkkaya N, Çaylan R, Köksal İ. Klinik Örneklerden İzole Edilen Enterobacter Suşlarının Çeşitli Antibiyotiklere Direnç Oranları. Türk Mikrobiyoloji Cemiy Derg. 2004;34:29-32.
20. Gülhan B, Nergiz Ş, Meşe S, et al. Antimicrobial Resistance Between 2005-2007 in Enterobacter Strains. In: 23ANKEM Antibiyotik ve Kemoterapi Kongresi; Çeşme, İzmir. 2008:14.

21. Tarumoto N, Kodana M, Watanabe N, et al. First report of the isolation of blaIMI-1-producing colistin-heteroresistant Enterobacter cloacae in Japan, September 2016. J Infect Chemother. 2018;24(11):941-943.

22. Band VI, Crispell EK, Napier BA, et al. Antibiotic failure mediated by a resistant subpopulation in Enterobacter cloacae. Nat Microbiol. 2016;1(6):16053.

23. Norgan AP, Freese JM, Tuin PM, et al. Carbapenem- and ColistinResistant Enterobacter cloacae from Delta, Colorado, in 2015. Antimicrob Agents Chemother. 2016;60(5):3141-3144. 